\title{
Impact of Body Mass Index on Gastrointestinal Disorders: A Cross-sectional Study in a Pakistani Population
}

\author{
Shahid Ahmed Sr. ${ }^{1}$, Hafeezullah Shaikh ${ }^{2,3}$, Sajjad Jamil ${ }^{4}$, Hamid Ali ${ }^{4}$, Maryam Abbasi Jr. ${ }^{5}$ \\ 1. Internal Medicine, Darul Sehat Hospital, Karachi, PAK 2. Gastroenterology, Zubaida Medical Centre, Karachi, PAK 3. \\ Gastro, National Institute of Liver GI Diseases (NILGID), Dow University Hospital (DUH), Karachi, PAK 4. \\ Gastroenterology, Liaquat National Hospital \& Medical College, Karachi, PAK 5. Miscellaneous, Darul Sehat Hospital, \\ Karachi, PAK
}

Corresponding author: Hafeezullah Shaikh, hafeezmurad@gmail.com

\begin{abstract}
Background: The prevalence of obesity is on the rise globally. Pakistan ranks ninth out of 188 countries in terms of obesity. Literature regarding any potential role of obesity in gastrointestinal manifestations is limited. Besides, scarce information is available on possible connection between obesity and gastrointestinal pathology. This research, therefore, explores the impact of body mass index (BMI) on gastrointestinal symptoms and endoscopic discoveries.
\end{abstract}

Methods: A cross-sectional study was conducted at Darul Sehat Hospital, Zubaida Medical Centre, and Liaquat National Hospital \& Medical College, Karachi, Pakistan from $1^{\text {st }}$ July 2017 to $30^{\text {th }}$ November 2018. Patients scheduled to undergo endoscopy were surveyed before the procedure in which they were asked about demographics, comorbid, and gastrointestinal manifestations. The association between BMI and endoscopic findings and related gastrointestinal symptoms was assessed using Pearson chi square test and binary logistic regression. The significance level was set at 0.05 .

Results: A total of 2148 subjects were included in the study out of which $20.2 \%$ were overweight (BMI 2324.9 ) and $20.9 \%$ subjects were obese (BMI $>25$ ). Both the gastrointestinal symptoms and endoscopic findings were found to be significantly associated with the BMI ( $p<0.05$ for both). Moreover, binary logistic regression revealed obesity to be a significant contributor of abnormal endoscopic findings (adjusted odds ratio, AOR, 2.93; 95\% confidence interval, CI, 2.35-3.65).

Conclusion: Based on the study results, obesity was identified as a risk factor associated with gastrointestinal symptoms like gastro esophageal reflux disease (GERD) and other related gastrointestinal conditions such as erosive gastritis, duodenal ulcers, reflux esophagitis, and large hiatal hernia.

Received 03/23/2020

Review began 03/27/2020 Review ended 04/13/2020 Published 04/18/2020

(c) Copyright 2020

Ahmed et al. This is an open access article distributed under the terms of the Creative Commons Attribution License CC-BY 4.0., which permits unrestricted use, distribution, and reproduction in any medium, provided the original author and source are credited.
Categories: Gastroenterology, Epidemiology/Public Health

Keywords: body mass index, gerd, obesity, gastritis, duodenal ulcers

\section{Introduction}

The prevalence of obesity is on the rise globally. According to World Health Organization, per capita weight has dramatically increased worldwide since 1980 and in 2016, more than 1.9 billion people aged 18 years or above were overweight while more than 600 million grown-ups were obese worldwide [1]. In Pakistan, increased weight has become a significant danger to clinical wellbeing of individuals and as indicated by the Global Weight of Disease study, Pakistan is positioned ninth out of 188 nations in terms of obesity [2]. Obesity is considered a risk factor for many noncommunicable diseases such as diabetes, hypertension, coronary illness, stroke, and gall stones [3-5]. Moreover, as indicated by The American Institute for Cancer Research there is persuading proof for a connection between obesity and a few types of cancers like esophageal cancer, liver malignancy, postmenopausal breast tumor, gastrointestinal cancers, and colorectal malignancies [6].

Any potential role of obesity in the development of gastrointestinal symptoms is unclear and literature reveals equivocal findings in this regard. Increased body mass index (BMI) has earlier been reported to be associated with upper abdominal pain, gastro esophageal reflux, and indigestion but not with lower abdominal pain, nausea, and vomiting [7]. It is known that the occurrence of heartburn and regurgitation in obese individuals is due to excessive transient lower esophageal sphincter relaxation during the postprandial period, which results in elevated esophageal acid exposure [8]. Moreover data from a review published in 2013 demonstrate that weight reduction can result in resolution of gastro esophageal reflux ailment manifestations [9].

Other than upper gastrointestinal manifestations, any available data on a potential relationship between 
increased weight and other gastrointestinal pathology are scarce and conflicting [10-11].

The objective of the current study was, therefore, to assess the relationship between increasing BMI, gastrointestinal symptoms, and endoscopic findings in Pakistani population.

\section{Materials And Methods}

A prospective, cross-sectional study was conducted at Darul Sehat Hospital, Zubaida Medical Centre, and Liaquat National Hospital \& Medical College, Karachi, Pakistan from 1st July 2017 to 30th November 2018. The calculated sample size using 3\% prevalence, at $0.725 \%$ precision and $95 \% \mathrm{CI}$ was 2123 and to accommodate for nonresponders this was inflated by $1 \%-2 \%$ and 2148 individuals, aged 18 years or above, finally consented to participate in this study. Individuals with any comorbidity like diabetes, hypertension and chronic liver disease or history of cancer, inflammatory bowel disease, celiac disease, history of Helicobacter pylori eradication were excluded from the study. Participants who had been medicated with acid suppressing drugs like $\mathrm{H} 2$ receptor blockers, proton pump inhibitors, and nonsteroidal antiinflammatory drugs during the previous month were also excluded from our study.

Prior to endoscopy a questionnaire was administered in which patients were asked about demographics details such as age, height, and weight. Patients were also asked to score gastrointestinal symptoms over the past four weeks by a validated gastrointestinal symptoms rating scale (GSRS) [12]. In this questionnaire they were asked about specific symptoms like epigastric pain, heartburn, regurgitation, bloating, nausea, lower abdominal pain after a meal, after defecation, diarrhea, etc. They were further asked to rate the severity of these symptoms as no, mild, moderate, quite a lot, severe, very severe, and unbearable symptoms. The symptoms were then grouped into three categories: gastro esophageal reflux disease (GERD) (which was defined as heartburn and regurgitation), dyspepsia (which included symptoms of epigastric pain, abdominal bloating, and nausea), and lower abdominal symptoms (which included pain in the lower abdomen after a meal, when hungry, after defecation, diarrhea, and constipation).

Body mass index was calculated as the body weight $(\mathrm{kg})$ divided by square of height $(\mathrm{m})$ and categorized as underweight (BMI $<18.5 \mathrm{~kg} / \mathrm{m} 2$ ), normal (BMI $18.5-22.9 \mathrm{~kg} / \mathrm{m} 2$ ), overweight (BMI $23-24.9 \mathrm{~kg} / \mathrm{m} 2$ ), and obese (BMI $>25 \mathrm{~kg} / \mathrm{m} 2)$ [13-14].

The patients then underwent upper gastrointestinal endoscopic examination and the endoscopic findings were confirmed by pathology reports. Prior to endoscopy and questionnaire administration patients were asked to give written informed consent. Approval was taken from Ethical Review Committee of the Darul Sehat hospital.

Data were stored and analyzed using IBM-SPSS version 21. Frequencies and percentages were generated for descriptive analysis whereas association of gastrointestinal symptoms and endoscopic findings was assessed using Pearson chi square test. Binary logistic regression analysis was done to module the odds ratio with 95\% confidence interval (CI) for endoscopic findings (normal, not-normal); pie and bar chart was used for graphical presentation of data whereas p-value less than 0.05 was considered significant.

\section{Results}

Out of 2148 individuals included in the study $51.8 \%$ were aged $<40$ years, $52.8 \%$ were male, $11.3 \%$ were underweight, $20.2 \%$ were overweight whereas $20.9 \%$ were found to be obese (Table 1 ). 


\section{Cureus}

\begin{tabular}{|l|l|l|l|}
\hline Variables & & $\mathrm{n}$ & $\%$ \\
\hline Age group & $<=40$ years & 1112 & 51.8 \\
\hline & $>40$ Years & 1036 & 48.2 \\
\hline Gender & Male & 1134 & 52.8 \\
\hline & Female & 1014 & 47.2 \\
\hline BMI & Normal (<18.5) & 1022 & 47.6 \\
\hline & Underweight (18.5-22.9) & 243 & 11.3 \\
\hline & Over-weight $(23-24.9)$ & 433 & 20.2 \\
\hline & Obese (>25) & 450 & 20.9 \\
\hline
\end{tabular}

TABLE 1: Baseline characteristics of patients $(n=2148)$.

BMI, body mass index

The study results further revealed that both the gastrointestinal symptoms and endoscopic findings were significantly associated with the BMI ( $\mathrm{p}<0.05$ for both). Among gastrointestinal symptoms only the prevalence of GERD was the highest in obese individuals (48.9\%) while that of dyspepsia was the highest in underweight individuals (53.1\%) and that of lower abdominal symptoms was the highest in normal weight individuals (29.7\%). Among endoscopic findings the prevalence of all of the erosive gastritis, duodenal ulcers, reflux esophagitis, and large hiatal hernia were found to be the highest in obese individuals (15.6\%, $5.8 \%, 18.2 \%$, and $8.2 \%$ respectively), that of gastric ulcers was the highest in overweight individuals (3.5\%) whereas that of nonerosive duodenitis was the highest in underweight individuals (9.5\%) (Figures 1-2) (Table 2).

\begin{tabular}{|c|c|c|c|c|c|c|c|c|c|c|}
\hline \multirow{3}{*}{ Variables } & & \multicolumn{8}{|l|}{ BMI } & \multirow{3}{*}{ p-value } \\
\hline & & \multicolumn{2}{|c|}{ Normal } & \multicolumn{2}{|c|}{ Underweight } & \multicolumn{2}{|c|}{ Overweight } & \multicolumn{2}{|c|}{ Obese } & \\
\hline & & $\mathrm{n}$ & $\%$ & $\mathbf{n}$ & $\%$ & $\mathbf{n}$ & $\%$ & $\mathrm{n}$ & $\%$ & \\
\hline \multirow{3}{*}{ Gastrointestinal symptoms } & GERD & 389 & 38.1 & 113 & 46.5 & 189 & 43.6 & 220 & 48.9 & \multirow{3}{*}{$<0.01^{*}$} \\
\hline & Dyspepsia & 329 & 32.2 & 129 & 53.1 & 149 & 34.4 & 154 & 34.2 & \\
\hline & Lower abdominal symptoms & 304 & 29.7 & 1 & 0.4 & 95 & 21.9 & 76 & 16.9 & \\
\hline \multirow{7}{*}{ Endoscopic findings } & Normal & 717 & 70.2 & 163 & 67.1 & 194 & 44.8 & 184 & 40.9 & \multirow{7}{*}{$<0.01^{*}$} \\
\hline & Erosive gastritis & 80 & 7.8 & 24 & 9.9 & 61 & 14.1 & 70 & 15.6 & \\
\hline & Gastric ulcers & 12 & 1.2 & 0 & 0 & 15 & 3.5 & 9 & 2 & \\
\hline & Duodenal ulcers & 4 & 0.4 & 0 & 0 & 24 & 5.5 & 26 & 5.8 & \\
\hline & Reflux esophagitis & 107 & 10.5 & 33 & 13.6 & 68 & 15.7 & 82 & 18.2 & \\
\hline & Nonerosive duodenitis & 66 & 6.5 & 23 & 9.5 & 38 & 8.8 & 42 & 9.3 & \\
\hline & Large hiatal hernia & 36 & 3.5 & 0 & 0 & 33 & 7.6 & 37 & 8.2 & \\
\hline \multicolumn{11}{|c|}{ BMI, body mass index; GERD, gastro esophageal reflux disease } \\
\hline \multicolumn{11}{|c|}{${ }^{*} \mathrm{p}<0.05$ was considered significant using Pearson chi square test } \\
\hline
\end{tabular}




\section{Cureus}

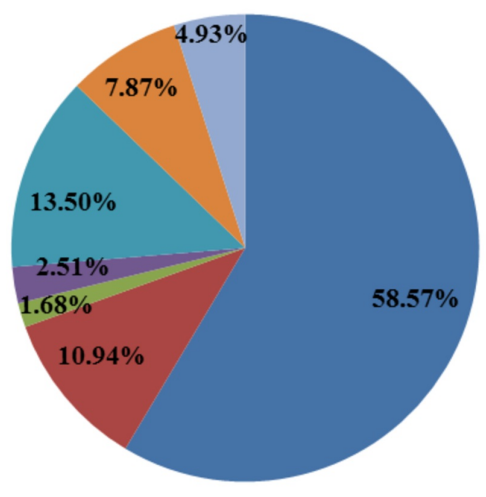

- Normal

Erosive Gastritis

Gastric ulcer

- Duodenal ulcer

- Reflex esophagitis

Non erosive duodenitis

- Large hiatal hernia

FIGURE 1: Frequency of endoscopic findings in patients $(n=2148)$.

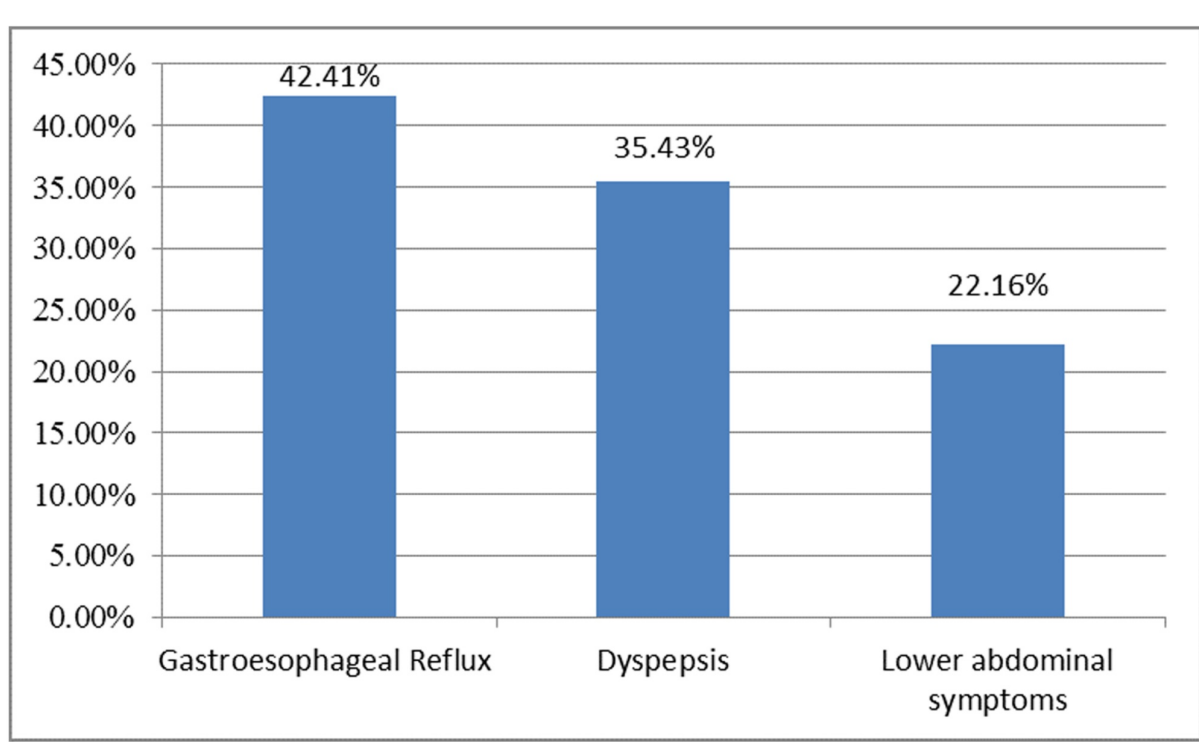

FIGURE 2: Frequency of gastrointestinal symptoms ( $n=2148)$.

Moreover, binary logistic regression revealed obesity to be a significant contributor of abnormal endoscopic findings after controlling for the potential confounding effects of age and gender (adjusted odds ratio, AOR, 2.93; 95\% CI, 2.35-3.65) (Table 3). 


\section{Cureus}

\begin{tabular}{|c|c|c|}
\hline Risk factors & Un-adjusted OR with $95 \% \mathrm{Cl}$ & Adjusted*^ OR with $95 \% \mathrm{Cl}$ \\
\hline Underweight & $1.15(0.85-1.55)$ & $1.22(0.89-1.68)$ \\
\hline Overweight & $2.9^{*}(2.3-3.66)$ & $0.83(0.63-1.11)$ \\
\hline Obese & $3.4^{\star}(2.7-4.29)$ & $2.93^{\star}(2.35-3.65)$ \\
\hline Dyspepsia & $0.96(0.79-1.16)$ & $0.96(0.79-1.16)$ \\
\hline Lower abdominal sy & $11(0.81-1$ & $.99(0.7$ \\
\hline
\end{tabular}

TABLE 3: OR with $95 \% \mathrm{Cl}$ for endoscopic findings.

OR, odds ratio; $\mathrm{Cl}$, confidence interval

*Odds were significant with $\mathrm{p}$-value $<0.05$

${ }^{\star *}$ Model adjusted for age and gender

\section{Discussion}

The objective of the current study was to assess the relationship between increasing BMI, gastrointestinal symptoms, and upper gastrointestinal disorders in patients referred for endoscopy.

The prevalence of obesity has increased drastically all over the world. Obese patients are at danger of cardiovascular illness and unexpected losses. Obesity is reported to increase the risk of morbidity by both traditional (dyslipidemia, hypertension, and glucose dysmetabolism) and less conventional mechanisms. Less conventional risk factors include enzymes secreted by adipocytes and macrophages infiltrating adipose tissue such as adipokines, proinflammatory cytokines, and lypofibrinolytic factors that together might lead to increased oxidative stress and endothelial dysfunction thereby finally promoting atherosclerosis. At the point when established hazard variables like smoking are superimposed on the insulin resistant state of obesity they may additionally increase less conventional risk factors intensifying the existing cardiovascular issues [15].

Literature reports equivocal findings about the relationship of gastrointestinal symptoms and disorders with BMI. A systematic review reported a positive relationship between increasing BMI and the presence of GERD within the United States with an odds ratio of 1.57 for overweight and 2.15 for obese individuals [16]. In another review $79 \%$ obese people revealed reflux manifestations when contrasted with $48 \%$ normal weight people; $40 \%$ of the obese patients reported abdominal pain when contrasted with $25 \%$ normal weight patients [17]. Our outcomes are well in line with these reviews. In our study $48.9 \%$ obese individuals reported GERD symptoms, $34.2 \%$ had dyspepsia while $16.9 \%$ reported lower abdominal symptoms. Contrary to the study results, a review published in Netherlands demonstrated no significant relationship between increasing BMI and gastrointestinal symptoms [11]. This could be because of distinction in our way of life, dietary patterns, and constrained physical activity.

In Pakistan, the prevalence of gastrointestinal disorders is on the rise but only a limited number of patients are referred for endoscopy because of their poor financial status as endoscopy is a costly method and exorbitant for countless patients presenting with gastrointestinal symptoms. The relationship amongst BMI and upper gastrointestinal diseases has been explored earlier in studies published in West, however, to the best of authors' knowledge no relevant study has previously been done in South Asia, including Pakistan. This study, therefore, is believed to be the first of its kind exploring such a relationship in Pakistan. One of the review by El-Serag et al. showed a significant increase in erosive esophagitis in people with higher BMI (26.9\% in people with BMI $>30 \mathrm{~kg} / \mathrm{m} 2$ had reflux esophagitis when contrasted with $12.5 \%$ in people with $\mathrm{BMI}<25 \mathrm{~kg} / \mathrm{m} 2$ ) [18]. Another review demonstrated that esophagitis was altogether more predominant in obese (26.5\%) than in normal people (9.3\%) while duodenal ulcer was present in $2.5 \%$ of obese people [19]. We did, however, find reflux esophagitis as well as other gastrointestinal symptoms to be more prevalent in patients with higher BMI. In our study, $15.6 \%$ of obese patients had erosive gastritis when contrasted with $7.8 \%$ normal weight patients, $5.8 \%$ obese patients had duodenal ulcer when contrasted with $0.4 \%$ normal weight patients, and $18.2 \%$ obese patients had reflux esophagitis when contrasted with $10.5 \%$ normal weight patients. Despite asking for the medication history of the participants, unrecognized medications, for example, NSAID and medicine for the treatment of obesity (orlistat) might have confounded the observed associations.

\section{Conclusions}

The study results revealed that some of the gastrointestinal manifestations studied occurred more frequently 
in obese patients. Additionally, obese patients are at danger of developing gastrointestinal disorders like reflux esophagitis, duodenal ulcers, erosive gastritis, and hiatal hernia. Keeping in view the results of this review, endeavors ought to be made to promote lifestyle modifications, exercise, and weight reduction for preventing gastrointestinal disorders.

\section{Additional Information \\ Disclosures}

Human subjects: Consent was obtained by all participants in this study. Ethics Review Committee, Darul Sehat Hospital issued approval _. Animal subjects: All authors have confirmed that this study did not involve animal subjects or tissue. Conflicts of interest: In compliance with the ICMJE uniform disclosure form, all authors declare the following: Payment/services info: All authors have declared that no financial support was received from any organization for the submitted work. Financial relationships: All authors have declared that they have no financial relationships at present or within the previous three years with any organizations that might have an interest in the submitted work. Other relationships: All authors have declared that there are no other relationships or activities that could appear to have influenced the submitted work.

\section{References}

1. Obesity and overweight [Internet]. (2017). Accessed: February 4, 2018: http://www.who.int/mediacentre/factsheets/fs311/en/.

2. Ng M, Fleming T, Robinson M, et al.: Global, regional, and national prevalence of overweight and obesity in children and adults during 1980-2013: a systematic analysis for the Global Burden of Disease Study 2013. Lancet. 2014, 384:766-781. 10.1016/S0140-6736(14)60460-8

3. Field AE, Coakley EH, Must A, et al.: Impact of overweight on the risk of developing common chronic diseases during a 10-year period. Arch Intern Med. 2001, 161:1581-1586. 10.1001/archinte.161.13.1581

4. Zafar J, Nadeem D, Khan SA, Jawad Abbasi MM, Aziz F, Saeed S: Prevalence of diabetes and its correlates in urban population of Pakistan: a cross-sectional survey. J Pak Med Assoc. 2016, 66:922-927.

5. Mandal A: Study of prevalence of type 2 diabetes mellitus and hypertension in overweight and obese people. J Fam Med Prim Care. 2014, 3:25-28.

6. Obesity and cancer risk [Internet]. (2018). Accessed: January 31, 2018: http://www.aicr.org/reduce-yourcancer-risk/weight/reduce_weight_cancer_link.html.

7. Eslick GD: Gastrointestinal symptoms and obesity: a meta-analysis. Obesity Rev. 2012, 13:469-479.

8. Wu JC, Mui LM, Cheung CM, Chan Y, Sung JJ: Obesity is associated with increased transient lower esophageal sphincter relaxation. Gastroenterology. 2007, 132:883-889. 10.1053/j.gastro.2006.12.032

9. Singh M, Lee J, Gupta N, et al.: Weight loss can lead to resolution of gastroesophageal reflux disease symptoms: a prospective intervention trial. Obesity. 2013, 21:284-290. 10.1002/oby.20279

10. Corley DA, Kubo A, Levin TR, et al.: Abdominal obesity and body mass index as risk factors for Barrett's esophagus. Gastroenterology. 2007, 133:34-41. 10.1053/j.gastro.2007.04.046

11. Van Oijen MG, Josemanders DF, Laheij RJ, Van Rossum LG, Tan AC, Jansen JB: Gastrointestinal disorders and symptoms: does body mass index matter?. Neth J Med. 2006, 64:45-49.

12. Bovenschen HJ, Janssen MJ, Van Oijen MG, Laheij RJ, Van Rossum LG, Jansen JB: Evaluation of a gastrointestinal symptoms questionnaire. Dig Dis Sci. 2006, 51:1509-1515.

13. World Health Organization: The Asia-Pacific Perspective: Redefining Obesity and Its Treatment . Health Communications Australia (ed): Sydney; 2000.

14. Choo V: WHO reassesses appropriate body-mass index for Asian populations. Lancet. 2002, 360:235 10.1016/S0140-6736(02)09512-0

15. Van Gaal LF, Mertens IL, Christophe E: Mechanisms linking obesity with cardiovascular disease. Nature. 2006, 13:875.

16. Corley DA, Kubo A: Body mass index and gastroesophageal reflux disease: a systematic review and metaanalysis. Am J Gastroenterol. 2006, 101:2619.

17. Huseini M, Wood GC, Seiler J, et al.: Gastrointestinal symptoms in morbid obesity. Front Med. 2014, 1:49. 10.3389/fmed.2014.00049

18. El-Serag HB, Graham DY, Satia JA, Rabeneck L: Obesity is an independent risk factor for GERD symptoms and erosive esophagitis. Am J Gastroenterol. 2005, 100:1243.

19. Aro P, Ronkainen J, Talley NJ, Storskrubb T, Bolling-Sternevald E, Agréus L: Body mass index and chronic unexplained gastrointestinal symptoms: an adult endoscopic population based study. Gut. 2005, 54:13771383. 10.1136/gut.2004.057497 